\title{
Transmission Characteristics Simulation on Power Line Communications
}

\author{
Masashi Kitayama Senior Member (Mitsubishi Electric Corporation) \\ Miyuki Nakabayashi Member (Mitsubishi Electric Corporation) \\ Junichi Abe Non-member (Mitsubishi Electric Corporation) \\ Shinji Tanabe Non-member (Mitsubishi Electric Corporation)
}

Keywords : power line communications, channel model, transmission characteristics, two port network, distribution network model

In Power Line Communication (PLC) systems, medium and low voltage power distribution lines are used as a communication network. However, since no consideration is given to signal transmission characteristics in the high frequency used for PLC systems, reflections caused by impedance mismatches deteriorate transmission characteristics. If channel characteristics of power lines can be estimated by simulation, it will be efficient for the design and the operation of PLC networks. This paper proposes a method to estimate transmission characteristics of a channel model between a transmitter and a receiver installed on a distribution network. Propagation characteristics of PLC signals at each distribution facility is described using two port networks. A channel model is automatically generated from the combination of component models along the topology of distribution network and the locations of a transmitter and a receiver.

For medium-voltage system configurations, systems typically employed are open loop, including loop topologies, which are typically opened in one place by an automatic switch or manual, and tree-like topology systems, which include radial distribution line. Depending on the way the electrical loads are distributed, distribution line types and lengths vary among power systems.

PLC network model generated from the combination of component models is described as a tree model whose root node is a power source as shown in Fig. 1. The input and output terminals of component models are defined correspond to the direction from the root to leaf node. The direction of component models is not the

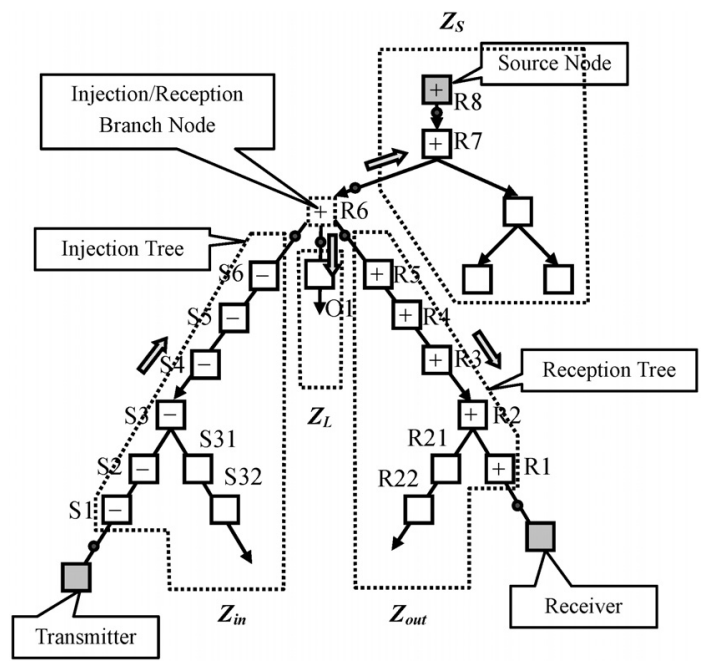

Fig. 1. Distribution network topology model same as the direction of the flow of PLC signal because the flow of PLC signal is depend on the location of a transmitter and receiver. The authors has developed the alogrithm to generate the direction of PLC singal from the location of the transmitter and receiver by tracing the tree from the transmitter and receiver forward the root node along the network topology.

The distribution network model is devided in four sections by the injection/reception branch node, which is the common ancestor node of the transmitter and the receiver. Each sections is reduced into one integrated component model by the matrix calculation of two port matircs. Transmission characteristics and the PHY rate from the transmitter to the receive can be estimated based on the reduced model shown in Figure 2.

Component models were validated using the test distribution network of the low-voltage system inlcuding several kinds of cables and a transformer. The S parameters and PHY rate was measured by a network analyzer and a PLC modems.Figure 3 shows the results of calculated and measured transmission characteristc. The results are almost same, which shows that the proposed method has been proved to be effective.

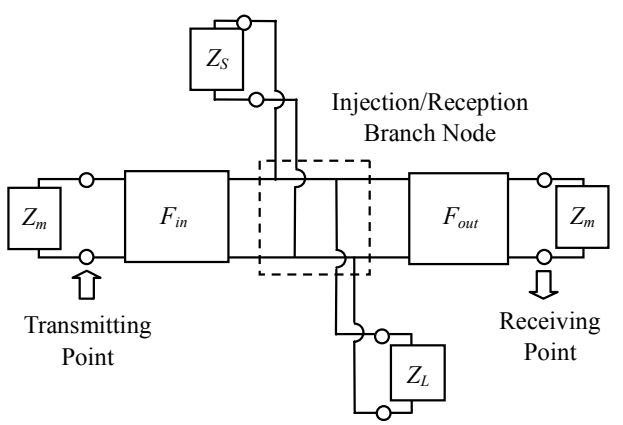

Fig. 2. Reduced network model

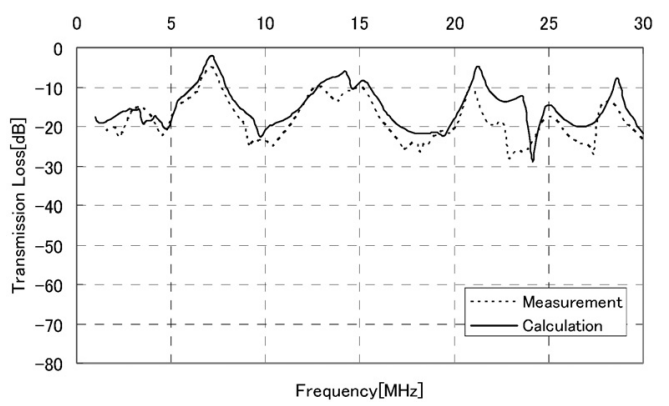

Fig. 3. Transmission Characteristics of calculation and measurement 


\title{
高速電力線通信における伝送特性シミュレーション
}

$\begin{array}{llll}\text { 上級会員 北山 } & \text { 匡史* } & \text { 正 員 仲林 見幸* } \\ \text { 非会員 安部 } & \text { 淳一* } & \text { 非会 員 田邊 信二* }\end{array}$

\author{
Transmission Characteristics Simulation on Power Line Communications \\ Masashi Kitayama*, Senior Member, Miyuki Nakabayashi*, Member, Junichi Abe*, Non-member, \\ Shinji Tanabe*, Non-member
}

In Power Line Communication (PLC) systems, medium and low voltage power distribution lines are used as a communication network. However, since no consideration is given to signal transmission characteristics in the high frequency used for PLC systems, reflections caused by impedance mismatches deteriorate transmission characteristics. If channel characteristics of power lines can be estimated by simulation, it will be efficient for the design and the operation of PLC networks. This paper proposes a method to estimate transmission characteristics of a channel model between a transmitter and a receiver installed on a distribution network. Propagation characteristics of PLC signals at each distribution facility is described using two port networks. A channel model is automatically generated from the combination of component models along the topology of distribution network and the locations of a transmitter and a receiver. The proposed method was validated using measurement data of a test distribution network and was proved to be effective.

キーワード : 電力線通信, 伝送路モデル, 伝送特性, 二端子対回路, 配電系統モデル

Keywords : power line communications, channel model, transmission characteristics, two port network, distribution network models

\section{1. はじめに}

海外における高速電力線通信(Power Line Communications) の適用例として，電圧階級が $10 \sim 30 \mathrm{kV}$ 級の中圧( $\mathrm{MV}$ : Medium Voltage)・100/200/400V 級の低圧(LV: Low Voltage)配 電線を通信ネットワークとしてインターネットアクセスな どの用途に用いるアクセス系ネットワークがあげられ $ろ^{(1)(2)}$ 。配電系統はもともと高速 PLC で用いる周波数帯域(2 〜30MHz)における信号伝送特性は考慮されて設計されてい ないため，インピーダンス不整合による反射に起因する伝 送特性の劣化が発生する。伝送特性を計算機シミュレーシ ヨンによって検討することができれば，伝送困難と推定さ れる場所に対する対策検討, PLC ネットワークの設計・運 用の効率化が期待される。

このような背景から，筆者らは高速 PLC の信号伝送特性 を計算する手法の開発を行っている(3)(4)。PLC における伝送 特性の評価については，実フィールドでの実測による評価， 伝送路の解析モデルの構築など国内外でさまざまな検討が これまでになされている(5) (15)。これまでの検討では, 大き

* 三菱電機(株)

T661-8661 兵庫県尼崎市塚口本町 8-1-1

Advanced Technology R\&D Center, Mitsubishi Electric Corporation

8-1-1 Tsukaguchi-hommachi, Amagasaki, Hyogo 661-8661
く伝送路の解析モデルを構築する検討 ${ }^{(5) ~(13) ~} と$ 実測結果に 基づいた検討(14)(15)があげられる。これらは，主として宅内 通信を対象としたものである。宅外の配電系統を対象とし たものでは, 漏洩電界強度の評価のための解析モデル検討 がなされている(16)。しかし, 配電系統を対象とした通信性 能シミュレーションの検討はこれまでにほとんどなされて いない。

本研究では，まず，これまでの研究で得られた知見に基 づいて, アクセス系ネットワークを対象とした伝送特性モ デルの構築を行った。次に, 伝送特性を机上で推定するこ とを目的として, 配電線に伝送信号を結合するための信号 結合装置を配電系統の任意箇所に設置した場合に，伝送特 性モデルに基づくシミュレーション手法をソフトウェアで 実装するためのデータモデルとシミュレーションロジック について検討を行った。このようなソフトウェアの実装で は, 配電系統の機器接続情報をデータベース化し, 結合装 置の設置位置と機器接続情報から伝送特性を推定するのに 必要な伝送路モデルを生成する方法が課題となる。本稿で は, 配電系統のトポロジーに基づく伝送路モデルの構築方 法および伝送路モデルを用いた伝送特性シミュレーション 方法を提案する。シミュレーション方法については, 電力 線通信においてもっともよく使われる OFDM 通信方式を評 
価するためのシミュレータも開発されている(17)。この研究 では，OFDM 通信方式の評価が主目的とされているのに対 し, 本研究では配電系統モデルから伝送路モデルを自動的 に生成して伝送特性のシミュレーションを実施する方法に ついて検討を行った。

提案する伝送特性シミュレーション方法の妥当性を検証 するため仮想的な配電系統モデルでの解析結果, およびシ ミュレーションの精度検証のために行った模擬配電系統で の伝送特性実測值とシミュレーション值を比較した結果に ついても述べる。

\section{2. 伝送特性シミュレーションの考え方}

宅外配電系統を対称とした電力線通信では，電力を送電 するためにもともと設置されている電線・変圧器 - 電力量 計などの配電機器に加え, 電力線通信信号の送受信装置, 注入・取出を行う信号結合装置を使用する。本稿では, こ れらの機器を総称して PLC 機器とよぶことにする。宅外配 電系統では, 中圧配電線から変圧器を介して低圧に降圧し, 低圧配電線によって需要家へ電力を供給する構成になって いる。したがって, 中圧配電系統を用いて電力線通信を用 いる場合, 分岐位置に変圧器が存在することになるため, 変圧器のモデル化が必要となる。

電力線通信における伝送路モデルの構築および伝送特性 の解析に関してこれまでになされた検討において，伝送路 モデル化の考え方は，大きく 2 通りに分けられる。1つは, 配電系統で測定した伝送特性をもとにして，減衰特性や伝 送遅延などのパラメータをモデルパラメータとして伝送特 性を同定するトップダウンアプローチである ${ }^{(5) \sim(7)}$ 。う 1 つは, 個々の配電機器について形状パラメータに基づく物 理モデルを同定し, 伝送路卜ポロジーに従って組み合わせ ることによって伝送路モデルを構築するボトムアップアプ ローチである ${ }^{(8) \sim(12)}$ 。前者のアプローチは, 実測データに基 づいてモデルを同定するため, 計算量が少なくてすむとい う利点がある一方で, 伝送路をブラックボックスとして扱 うため同定したパラメータの解釈が難しい場合もあり，測 定していない伝送路での伝送特性の推定が困難であるとい う久点がある。後者のアプローチは, 伝送路モデルを構築 するためには, 伝送路の構成要素であるすべての配電機器 に対する伝送特性を収集する必要があるという欠点がある 一方で，さまざまな伝送路に対する伝送特性を推定できる 可能性がある。

アクセス系ネットワークへの適用を考える場合，信号結 合装置は配電系統のなかでさまざまな位置に設置されるこ とが予想されるため, 伝送路としては多様なトポロジーと なりうることが想定されるので, 後者のアプローチが適当 と考えられる。そこで, 本研究では, 個々の PLC 機器の電 気特性をモデル化し, 信号注入位置から受信位置までのモ デルを組み合わせることによって，伝送特性のシミュレー ションを行う。

伝送特性シミュレーションのソフトウェア実装にあたっ
て, 下記の 2 種類のデータベースを構築する必要がある。 シミュレーション方法に合わせて, これらのデータモデル についても検討を行った。

(1) 個々の PLC 機器のモデルパラメータ

(2) PLC 機器の接続情報（トポロジー）

\section{3. コンポーネントモデルの開発}

〈3·1〉PLC 機器モデル化の考え方 本研究では, 信 号結合装置間の伝送路について, 伝送路を構成する個々の 要素の電気特性をモデル化したものをコンポーネントモデ ルとよぶことにする。コンポーネントモデル化の対象は, 配電機器の他, 送受信装置・信号結合装置・分岐部・終端 インピーダンスに相当する終端部とする。上述の通り, こ れらを総称して PLC 機器とよぶ。

一般に, ある入力に対する出力の電圧・電流の特性は, 図 1 のような 4 端子回路で表現することができる ${ }^{(18)}$ 。4 端子 回路の入力電圧 $V_{1}$, 入力電流 $I_{1}$, 出力電圧 $V_{2}$, 出力電流 $I_{2}$ とすれば, 適当な複素数パラメータ $A, B, C, D$ により, (1) 式のように $F$ 行列で表すことができる。

$$
\left[\begin{array}{c}
V_{1} \\
I_{1}
\end{array}\right]=\left[\begin{array}{ll}
A & B \\
C & D
\end{array}\right]\left[\begin{array}{c}
V_{2} \\
I_{2}
\end{array}\right]
$$

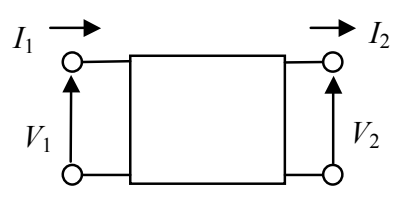

図 14 端子回路モデル

Fig. 1. Two port network model.

(a) Cascade combination of component models.

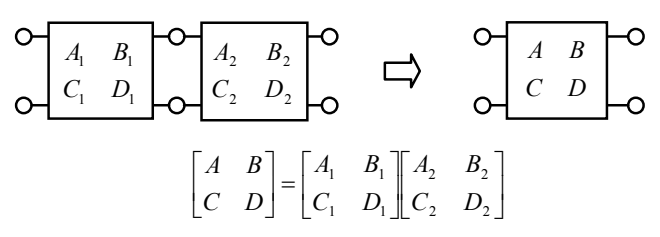

(b) Combination of component model and terminal impedance.

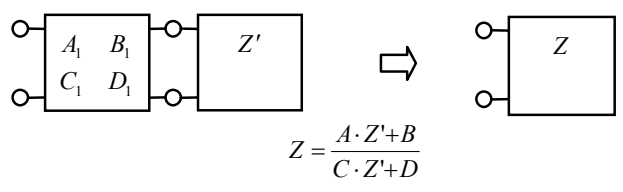

(c) Component model of series terminal impedance.

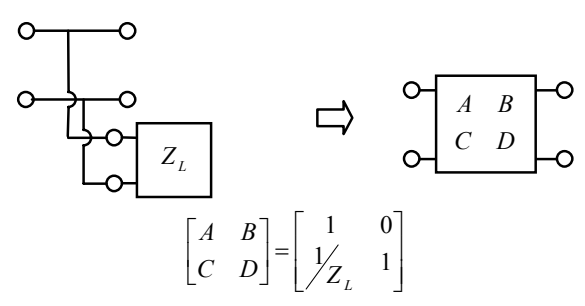

図 2 コンポーネントモデルの合成

Fig. 2. Integration of component models. 
$F$ 行列のパラメータは等価回路モデルより一意に求める ことができ, $F$ パラメータをコンポーネントモデルのモデル パラメータとする。各 PLC 機器でのモデルパラメータは, 周波数応答の実測值によって等価回路の定数を同定した。

PLC 機器をコンポーネントモデルで表現し，信号注入位 置から取出位置までの複数のコンポーネントモデルを一つ のコンポーネントモデルに合成して伝送特性を計算する。 コンポーネントモデルの合成は, PLC 機器の接続状態に応 じて, 図 2 に示すような演算を実施して行う。

PLC 機器のモデルパラメータをデータベース化すること を考慮すると, 複素数パラメータ $A, B, C, D$ の計算式お よびパラメータをデータモデルとする必要がある。

また，コンポーネントモデル $X$ に対して，入力と出力を 逆にしたコンポーネントモデル $X$ とすると, $X$ の $F$ パラメ 一タ $A, B, C, D$ と $X^{\prime}$ の $F$ パラメータ $A^{\prime}, B^{\prime}, C^{\prime}, D^{\prime}$ に, (2)式の関係が成り立つ。 $F^{-1}=F$ が成立すれば， $X$ のモデ ルパラメータを $A, B, C, D$ とすればよいが，成立しない 場合には， $X$ のモデルパラメータを $A, B, C, D$ とするか $A^{\prime}, B^{\prime}, C^{\prime}, D^{\prime}$ とするかいずれかを選択する必要がある。こ のためには, コンポーネントモデル $X$ の入力側・出力側を 定義する必要がある。コンポーネントモデルの入力側・出 力側の定義は, 4 章に説明するように, PLC 機器の接続情報 のモデル化の考え方に従って決定する。

$$
\left[\begin{array}{ll}
A^{\prime} & B^{\prime} \\
C^{\prime} & D^{\prime}
\end{array}\right]=\frac{1}{A D-B C}\left[\begin{array}{ll}
D & B \\
C & A
\end{array}\right] .
$$

本研究で対象とする配電系統は受動素子のみであるため 相反条件が成立し， $A D-B C=1$ となる。さらに，対象条件 も成立する場合には $A=D$ が成り立つため, コンポーネント モデル $X$ とコンポーネントモデル $X$ は同じ $F$ パラメータで 表現できるが, 対称条件が成立しない場合には $A=D$ となら ないため, $X$ と $X^{\prime}$ は一致しない。配電機器の中には, 変圧 器のように対称条件が成立しない場合も存在するため, コ ンポーネントモデルのデータを用意するときには, 2 つのポ 一トのうち $F$ パラメータと合わせて, 入力・出力のポート をセットにして定義する必要がある。

〈3·2〉 コンポーネントモデルの利点 本提案手法以 外の伝送特性計算方法として, SPICE などのツールによる 回路解析手法が考えられる。SPICE に代表される回路方程 式を解く方法に対して，コンポーネントモデルによる方法 では，伝送特性計算はコンポーネントの組み合わせ演算で あり，計算量が少なくてすむという利点があげられる。ま た, SPICE のような時間領域での解析では, 周波数依存性 のあるケーブル損失を直接考慮できないため, まずケーブ ル損失なしとして計算し，別途計算した損失を補正する必 要があるのに対し，コンポーネントモデルでは周波数依存 性を直接モデル化することができる。

コンポーネントモデルとしては, 配電機器のほかに, 母 線や分岐, 終端インピーダンスなど, 対応する配電機器は 存在しないが伝送路トポロジーを構成する要素として必要
な要素も構築した。

〈3·3〉電線のモデル化ＰLC 機器のモデル化の一例 として, 電線モデルについて以下に述べる。電線モデルに 用いるパラメータを表 1 に示す。

電線を図 3 のように分布定数回路として考える。 $R, L, C$, $G$ を, それぞれ単位長さあたりの配電線の抵抗, 自己イン ダクタンス, 静電容量, 漏れコンダクタンスとする。この とき, 配電線の $F$ パラメータ $A, B, C, D$ は, $(3)$ 式のよう に表される。

$$
A=D=\cosh \gamma l \quad B=Z_{0} \sinh \gamma l \quad C=\frac{1}{Z_{0}} \sinh \gamma l
$$

ただし， $\gamma$ は電線の伝搬定数であり, 減衰定数 $\alpha$ と位相 定数 $\beta$ で(4)式のように表される。

$$
r=\alpha+j \beta
$$

高速 PLC の周波数帯域 2 30MHz では, $R \ll \omega L, G \ll \omega C$ が成立する低損失線路と見なすことができ, $\alpha$ と $\beta$ は(5)(6) 式で近似的に計算できる。

$$
\begin{aligned}
& \alpha=\frac{1}{2}\left(R / Z_{0}+G Z_{0}\right) \\
& \beta=\omega \sqrt{L C}
\end{aligned}
$$

( 5 )式の抵抗 $R$ は( 7 )式で示すことができる。

$$
R=\frac{1}{\sigma S}
$$

ここで, $S$ は表皮効果を考慮した導体面積である。表皮深 さ $\xi$ は, 比透磁率を 1 とすると, (8)式で計算できる。

$$
\xi=\sqrt{\frac{1}{\pi f \mu_{0} \sigma}}
$$

また， (5)式のコンダクタンス $G$ は (9)式で示すことがで きる。

表 1 配電線モデルのパラメータリスト

Table 1. Parameters in transmission line model.

\begin{tabular}{|c|l|}
\hline Symbols & \multicolumn{1}{|c|}{ Description } \\
\hline \hline$\varepsilon_{r}$ & Relative dielectric constant of insulation sheath \\
\hline $\tan \delta$ & Loss factor of insulation sheath \\
\hline$Z_{0}$ & Complex characteristics impedance $(\Omega)$ \\
\hline$l$ & Length of conductor $(\mathrm{m})$ \\
\hline$a$ & Radius of conductor $(\mathrm{m})$ \\
\hline$d$ & Distance between conductors $(\mathrm{m})$ \\
\hline
\end{tabular}

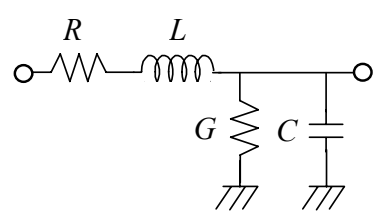

図 3 線路の微小区間の等価回路モデル

Fig. 3. Equivalent circuit model of transmission lines. 


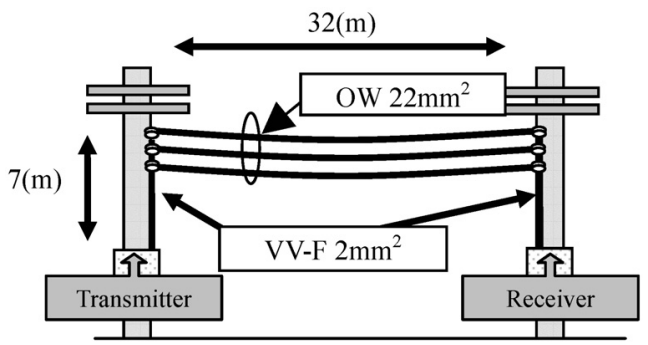

図 4 模擬配電系統

Fig. 4. Test distribution lines.

$$
G=2 \pi f C \tan \delta
$$

ただし, $\tan \delta$ は誘電正接, $C$ は電線閒の静電容量であり, 径の等しい平行 2 線間の静電容量は(10)式で計算できる。

$$
C=\frac{\pi \varepsilon_{r} \varepsilon_{0}}{\ln (d / a)}
$$

ここで, $\varepsilon_{0}$ は真空の誘電率, $d$ は平行 2 線の閒隔, $a$ は線 断面の直径を表す。

(6)式において，低損失線路では $\mathrm{LC}=\varepsilon \mu$ （ただし， $\varepsilon$ は 誘電率, $\mu$ は透磁率 $)$ が成り立つので, 比透磁率を 1 とする と，位相定数 $\beta$ は(11)式で計算できる。

$$
\begin{aligned}
& \beta=\omega \sqrt{L C}=\omega \sqrt{\varepsilon \mu}=\omega \frac{\sqrt{\varepsilon_{r}}}{c} \cdots \cdots . . . . . . . . \\
& \text { ここで, } \varepsilon \text { は真空中の光速を表す。 }
\end{aligned}
$$

〈3·4〉電線モデルの検証＼cjkstart構築した電線モデルを検 証するため, 図 4 の模擬配電系統を使って, ネットワーク アナライザによる実測結果と電線モデルによる計算結果, SPICE での解析結果を比較した。図 4 の模擬配電系統は三 芯の VV-F (PVC (Polyvinyl Chloride) insulated PVC sheathed cable-Flat type) ケーブルと単芯の OW (Outdoor Weather proof PVC insulated wire) ケーブルからなり, 分岐を含まない構成 になっている。電柱に沿って設置している 2 本の VV-F ケー ブルの両端にネットワークアナライザを接続して伝送特性 を測定した。ネットワークアナライザの測定ポートは不平 衡であるため，自作したバランを用いて VV-F ケーブルに接 続した。VV-F ケーブルの公称断面積は $2 \mathrm{~mm}^{2}$ であり, 比誘 電率と誘電正接については，厳密には周波数の関数となっ ているが，これまでの電線モデルのパラメータモデルに関 する研究結果(19)(20)などを参考として，それぞれ 3.1, 0.075 とした。また，OW ケーブルの公称断面積は $2 \mathrm{~mm}^{2}$ であり， 比誘電率と誘電正接については, 絶縁体が空気であるため それぞれ 1.0，0.0 とした。また，線路長は図 4 に示した通 りである。

図 5 に模擬配電系統での実測結果と解析結果を示す。図 に示すように，両者の結果はほぼ一致しており，構築した 電線モデルの妥当性を確認することができた。

〈3.5〉電線以外のモデル化＼cjkstart電線以外のモデルにつ いては, 系統から切り離した単体でネットワークアナライ ザによって $S$ パラメータを測定し $S$ パラメータから $F$ パラ メータに変換したデータを用いた。測定データの例として, $6600 \mathrm{kV} / 100 \mathrm{~V}$ の $50 \mathrm{kVA}$ の柱上変圧器について, 測定した $S_{11}$

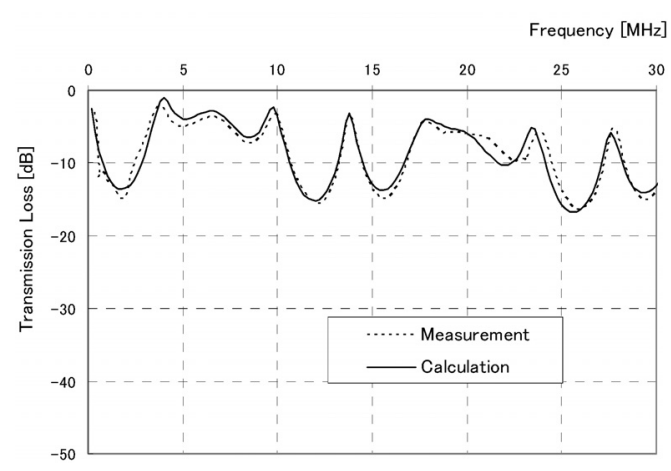

図 5 模擬配電系統における伝送特性の比較

Fig. 5. Comparison between measurements and calculated transmission characteristics.

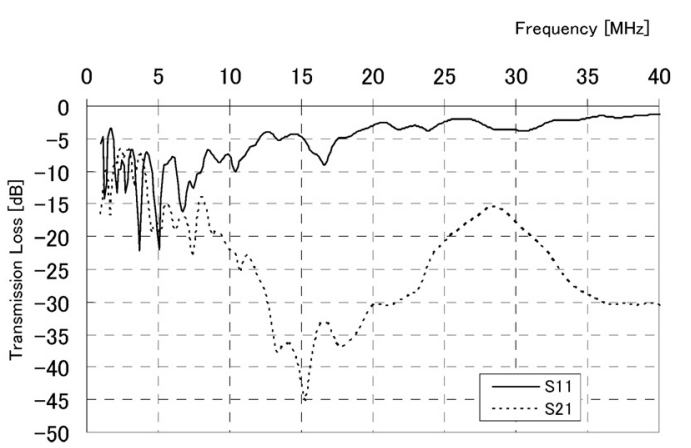

図 6 変圧器の $S$ パラメータの測定結果

Fig. 6. Measurements of $\mathrm{S}$ parameters of transformer.

と $S_{21}$ を図 6 に示す。

\section{4. 伝送特性計算方法}

〈4·1〉伝送路トポロジーのモデル化＼cjkstart本節では，デ ータモデルのうち PLC 機器の接続情報（トポロジー）のモ デル化について述べる。PLC 機器のうち, 配電系統を構成 する配電機器については, PLC 機器の接続情報については, 配電系統の構成を前提としたネットワークモデルとして構 築することを考える。

中圧配電系統（日本では高圧配電系統に相当）は，供給 信頼度を確保できるループ系統として構築され，運用とし ては常時 1 力所を開放したオープンループでの運用となっ ているのが一般的であり, トポロジーとしては放射状系統 となっている。本研究で伝送特性計算の対象とする配電系 統は放射状構成となっているものとする。配電機器の構成 は，例えば配電自動化システムなどで設備データベース化 されていることを考慮し, このような配電機器の接続情報 を活用するために, PLC 機器に対応するコンポーネントモ デルをノードとするツリー構造によって放射状構成をモデ ル化する。各ノードについて，電源側のノードを親ノード, 負荷側の複数のノードを子ノードとする。ノードの親子関 係を設定する理由は, 配電機器をコンポーネントモデル化 する場合, 変圧器など対称条件が成立しない機器が存在し, 入力側と出力側を設定したモデルとする必要があるためで 
ある。各コンポーネントモデルについて, 電源側を入力ポ ート, 負荷側を出力ポートとし, コンポーネントモデルに 対応する PLC 機器のモデルパラメータをデータベース化す る。

PLC 機器をトポロジーに従って組み合わせたネットワー クモデルを伝送路モデルとよぶ。伝送路モデルの例を図 7 に示す。図 7 において，R1〜R8, S1〜S6 のマークのある四 角が PLC 機器に対応するノードを表している。例えば，中 圧系統を模擬する場合には, R1〜R6, S6〜S1 までが電線で, $\mathrm{R} 21 \sim \mathrm{R} 22, \mathrm{~S} 31 \sim \mathrm{S} 32$ のような分岐は, 中圧系統の分岐の場 合や, 変圧器を介した低圧系統への分岐の場合などが考え られる。後者の場合, 分岐の R22 や S 32 に変圧器を接続す ることになる。送受信位置の四角には，実際には送受信装 置が設置され，送信位置から受信位置までの通信を行う。 配電系統は上位系統から発電設備まで接続したネットワー クであるが，送受信位置を含む範囲で配電系統を切り出し てモデル化を行っている。図 7 の例では，R8 がもっとも電 源側のノードとなっており, ツリー構造でのルートノード に相当する。このように，伝送特性シミュレーションに必 要なネットワークは, モデル化範囲でのもっとも電源側で ある電源端ノードをルートノードとするツリー構造として 表すことができる。

PLC 信号の流れる方向は送受信位置によって変化するた め, ツリー構造の親子関係, すなわちコンポーネントモデ ルの入出力の方向と信号の流れる方向は必ずしも一致しな い。そのため，伝送特性を計算する際には，送受信の位置 から信号の流れる向きを判定し，信号の流れる向きに応じ て 4 端子回路を合成する必要がある。本研究では, 配電系 統上に指定された任意の送受信位置に応じて，コンポーネ ントモデルの入出力関係と信号の流れる方向との関係を自 動的に判定して，伝送路モデルを構築するロジックについ て検討を行った。

$\langle 4 \cdot 2\rangle$ 伝送特性の計算本研究での伝送特性シミュ レーション方法では, 図 7 のように, 送信位置と受信位置 との共通の親ノードを「送受信分岐ノード」として設定し， 送受信分岐ノードでネットワーク全体 4 つの区間に分割す る。分割された区間ごとにコンポーネントモデルを合成し てトポロジーの縮約を行い, 縮約された伝送路モデルを用 いて伝送特性の計算を行う。伝送特性の計算手順を以下に 示す

（1）送受信分岐ノードの設定

まず，受信位置から親ノードを順にたどって，各ノード の信号の流れる向きを"+"に設定する。図 7 の例では, 受信 位置から R1，R2 と順に”+”に設定し，電源端ノードの R8 まで”+”設定する。なお， R8 はインピーダンスを持たない 分岐であり, 物理的に該当する PLC 機器は存在しないが, トポロジーモデル化の上で，分岐位置には必ず分岐ノード を設定する。

次に，送信位置から親ノードを順にたどって，各ノード の信号の流れる向きを"一"に設定する。図 7 の例では, 送信

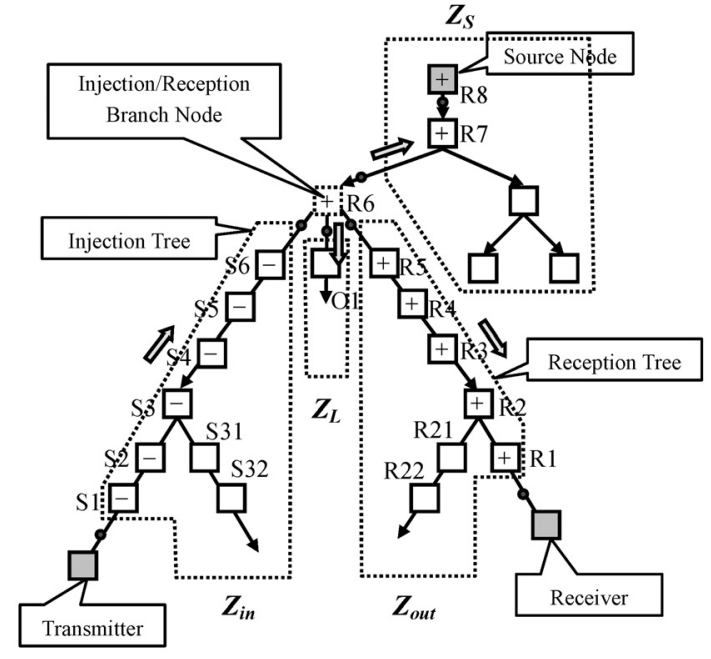

図 7 伝送路卜ポロジーのモデル化

Fig. 7. Distribution network topology model.

位置から S1，S2 と順に”—”に設定し，すでに”+”に設定さ れている R6 の前の S8 まで”—”を設定する。

再び，受信位置から親ノードを順にたどって，信号の流 れる向きが"一"に設定されているノードを探索し, 該当ノー ドを送受信分岐ノードに設定する。図 7 の例では, R6 が送 受信分岐ノードとなる。送受信分岐ノードの子ッリーのう ち, 送信位置につながるものを「送信側子ツリー」, 受信位 置につながるものを「受信側子ツリー」と呼ぶ。図 7 の例 では，R1〜R5，R21〜R22 が受信側子ツリー, S1〜S6, S31 ～S32 が送信側子ツリーとなる。子ツリーもやはりツリー構 造となっており, 受信側子ッリーのルートノードは R5, 送 信側子ツリーのルートノードは S6 となる。

また，送受信分岐ノードR6について，図 7 の例で O1 の ように受信側子ッリー, 送信側子ッリー以外の複数の分岐 がある場合，この分岐も同様にツリー構造として扱うこと ができ，「その他子ツリー」と呼ぶ。

(2) 受信側子ツリーのコンポーネントモデルの合成 送受信分岐ノードと受信位置の間に存在する $n$ 個のコン ポーネントモデル $X_{i}(i=1,2, \ldots, n)$ の $F$ 行列 $F_{i}$ とする。図 2(a)に従って, 受信側子ツリーの合成 $F$ 行列 $F_{\text {out }}$ を(12)式で 計算する。

$$
F_{\text {out }}=F_{1} \times F_{1} \times \cdots \times F_{n}
$$

図 7 の例では, 受信側子ツリーはルートノードから順に R5，R4，・, R1 と接続しているため, 合成 $F_{\text {out }}$ は $F_{\text {out }}=F_{R 5} F_{R 4} F_{R 3} F_{R 2} F_{R 1}$ となる。ただし, R2 は分岐ノードであ るため, 図 2(a)(b)にしたがってR21, R22 の合成インピーダ ンスを計算し, 図 $2(\mathrm{c})$ に従って $F_{R 2}$ を計算する。

(3) 送信側子ツリーのコンポーネントモデルの合成 受信側子ツリーと同様に, 送信側子ツリーの合成 $F$ 行列 $F_{\text {in }}$ を計算する。すなわち, 送受信分岐ノードと送信位置の 間に存在する $m$ 個のコンポーネントモデル $X_{i}(i=1,2, \ldots$. $m)$ の $F$ 行列 $F_{i}$ として, $F_{i n}$ を(13)式で計算する。

$$
F_{i n}=F_{m} \times F_{m-1} \times \cdots \times F_{1}
$$


ただし，送信側子ツリーでは，信号は $F$ パラメータの定 義と逆向き（子側から親側）に流れるので, (2)式で $F_{\text {in }}$ を $F_{\text {in }}$ 'に変換する必要がある。この $F_{\text {in }}$ 'を改めて $F_{\text {in }}$ として設 定する。図 7 の例では, 送信側子ツリーはルートノードか ら順に S6, S5，ㄱ, S1 と接続しているため, 合成 $F_{\text {out }}$ は $F_{\text {out }}=F_{S 6} F_{S 5} F_{S 4} F_{S 3} F_{S 2} F_{S 1}$ となる。ただし, S3 は分岐ノードで あるため, 図 2(a)(b)にしたがって S31，S32 の合成インピー ダンスを計算し，図 $2(\mathrm{c})$ に従って $F_{S 3}$ を計算する。

(4) 電源側合成インピーダンスの計算

送受信分岐ノードから電源側を見たときの合成インピー ダンス $Z_{S}$ を計算する。まず，送受信分岐ノードから電源端 の子ノードまでの合成 $F$ 行列 $F_{s r c}$ を計算する。この区間で も，送信側ツリー同様に，信号は逆向き（子側から親側） に流れるので, 送信側ツリーの合成 $F$ 行列 $F_{i n}$ と同様に計算 する。そして，図 2(b)にしたがって， $F_{s r c}$ と電源端の仮想イ ンピーダンス $Z_{0}$ を合成して， $Z_{S}$ を計算する。

(5) 負荷側合成インピーダンスの計算

送受信分岐ノードから送信側子ッリー・受信側子ッリー 以外の分岐であるその他子ツリーについて，負荷側を見た ときの合成インピーダンス $Z_{L}$ を計算する。まず，送受信分 岐ノードの $l$ 個の子ノード (送信側及び受信側子リンクの子 ノードを除く複数) について, 図 2(a)(b)にしたがって, 下 位側のコンポーネントモデルを合成して, 合成インピーダ ンス $Z_{L i}(i=1,2, \ldots, l)$ を計算する。そして，(14)式より $Z_{L}$ を計算する。

$$
Z_{L}=\frac{1}{\sum 1 / Z_{L i}}
$$

（6）送信位置から受信位置までの合成 $F$ 行列の計算

上記の手順によって，送信位置から受信位置までの伝送 路モデルは, 図 8 のように縮約される。この伝送路モデル を用いると, 送信位置から受信位置までの合成 $F$ 行列 $F_{\text {total }}$ は(15)式で与えられる。

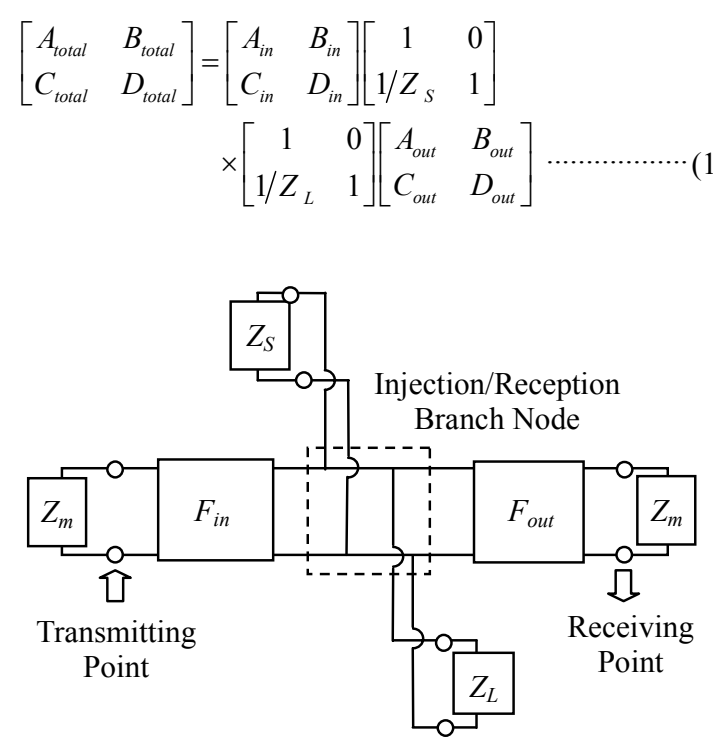

図 8 縮約した伝送路モデル

Fig. 8. Reduced network model.
ただし

$$
F_{\text {total }}=\left[\begin{array}{cc}
A_{\text {total }} & B_{\text {total }} \\
C_{\text {total }} & D_{\text {total }}
\end{array}\right] \quad F_{\text {in }}=\left[\begin{array}{cc}
A_{\text {in }} & B_{\text {in }} \\
C_{\text {in }} & D_{\text {in }}
\end{array}\right] \quad F_{\text {out }}=\left[\begin{array}{ll}
A_{\text {out }} & B_{\text {out }} \\
C_{\text {out }} & D_{\text {out }}
\end{array}\right]
$$

（7）送信位置から受信位置までの伝送特性の計算 送信位置から受信位置までの伝送特性は, 上記で計算し た $F_{\text {total }}$ を用いて，(16)式で与えられる。

$$
\begin{aligned}
H(f) & =20 \log \left|S_{21}\right| \\
& =20 \log \left|\frac{2}{A_{\text {total }}+B_{\text {total }} / Z_{m}+C_{\text {total }} \cdot Z_{m}+D_{\text {total }}}\right|
\end{aligned}
$$

ただし， $Z_{m}$ は信号結合装置を介した終端インピーダンス である。

〈4·3〉通信速度の計算 OFDM 方式での代表的な変 調方式である QAM では, 例えば 64QAM の場合での白色ガ ウス雑音に対するシンボル誤り率は次式で与えられる ${ }^{(21)}$ 。

$$
B E R=\frac{7}{24} \operatorname{erfc}\left(\sqrt{\frac{C / N}{42}}\right)
$$

ここで， $C$ は変調波の平均電力, $N$ はノイズの平均電力, $\operatorname{erfc}(x)$ は誤差余関数である。この式に基づき，ある設定され た BER 值に対して, SNR から 1 シンボル当たりの送信可能 ビット数を計算することができる。評価を行う周波数帯域 に対し，伝送特性シミュレーションにおいて伝送特性シミ ユレーションとノイズ特性との差で SNR を計算し, サブキ ヤリアごとの送信ビット数にシンボルレートを乗じること によって通信速度を計算することができる。

電力線通信の全体の $S / N$ を劣化させるのは主として広帯 域ノイズである。電力線でのノイズ特性は, 低い周波数ほ ぞ電力密度が高く, 周波数が高くなるにつれて減少すると 言われている(1)。本研究では, 統計的に優位なノイズ特性が 現時点では確率されていないため, 通信速度の計算では, 白色ガウス雑音を想定して $C / N$ 值を設定して計算を行った。

\section{5. 伝送特性シミュレーション方式の検証}

〈5-1〉伝送路モデル生成手法の検証 提案した伝送 路卜ポロジーモデル生成手法の有効性を検証するため, 図 9 の評価用系統において, 信号取出位置を固定とし, 信号注 入位置を異なる箇所に設置した 2 ケースを想定し, 生成さ れる伝送路モデルがどのようになるか検討を行った。図 9 の評価用系統は, 変圧器を含む中圧/低圧系統が混在する配 電系統を想定しており, OW ケーブルと CV ケーブルで構成 される。OW ケーブル，〈3·3 節で述べたもとと同じ公称断 面積が $22 \mathrm{~mm}^{2}$ のものである。CV ケーブルは, 公称断面積が $22 \mathrm{~mm}^{2}$ であり, 比誘電率・誘電正接は, VV-F ケーブル同じ で 3.1，0.075 とした。また，送受信装置はインピーダンス が $50 \Omega$ の終端とした。

ケース(a)は中圧系統で信号を送信し，低圧系統で信号を 受信するような異なる電圧階級の系統での伝送を想定した 


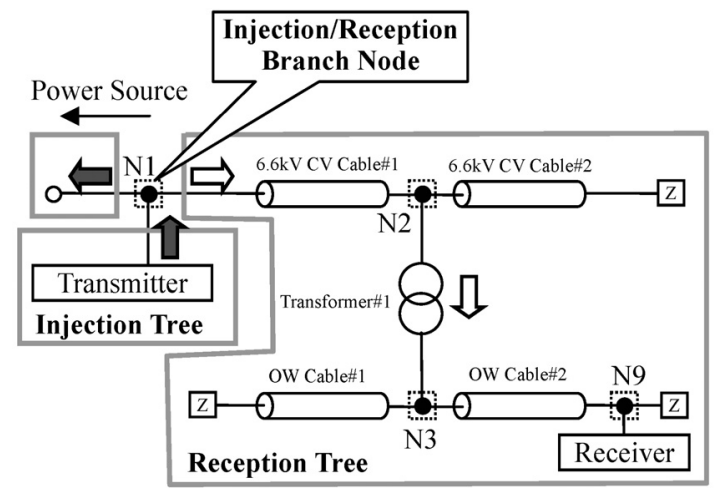

(a) Transmission from MV network to LV network.

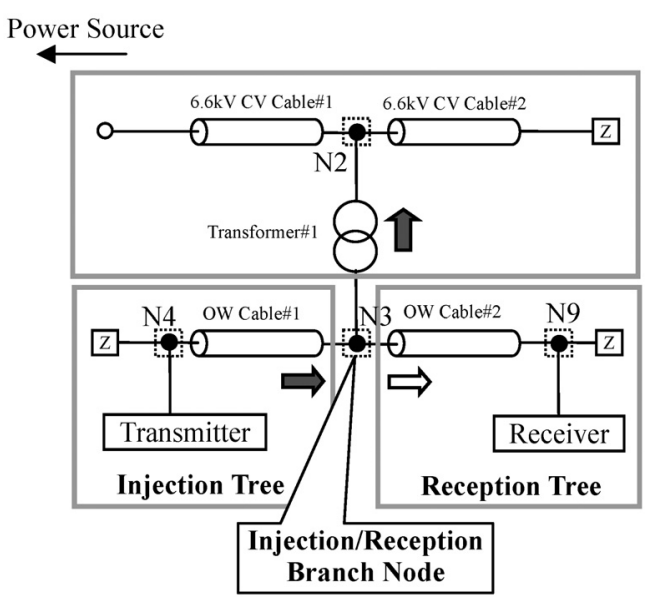

(b) Transmission in LV network.

図 9 伝送路卜ポロジーモデル評価用系統

Fig. 9. Test model for validation of topology model.

ケース，ケース(b)は低圧系統で信号を送信・受信するよう な同じ電圧階級の系統での伝送を想定したケースである。 ケース(a)では，信号送信位置のノードが送受信分岐ノード となり, 中圧/低圧変圧器では信号は中圧側から低圧側の順 方向へ流れる。一方, ケース(b)では中圧/低圧変圧器の 2 次 側が送受信分岐ノードとなり，信号は低圧側から中圧側の 逆方向一流れる。

ケース(a)では，受信位置からノードN9 であり，OW ケー ブル\#2, ノード N3, 変圧器\#1, ノード $\mathrm{N} 2, \mathrm{CV}$ ケーブル\#1, ノード N1 に”+”を設定する。一方，送信位置のノード N1 に”+”が設定されているため, 送受信分岐ノードはN1 とな り，受信側子ツリー・送信側子ツリーが図中に示したよう に設定される。このケースでは, 変圧器\#1について, $F$ パ ラメータはノード $\mathrm{N} 2$ が 1 次側であるため入力, ノード N3 側が 2 次側であるため出力としてデータが用意される。信 号の流れる方向もノード $\mathrm{N} 2$ からノード $\mathrm{N} 3$ であるため, $F$ パラメータの值をそのまま使用する。

ケース(b)では，受信位置からの”+”の設定はケース(a)と 同様である。一方，送信位置からノードN4, OW ケーブル \#1 に”一”が設定され, 送受信分岐ノードはN 3 となり, 受信 側子ツリー・送信側子ツリーは図中に示したようになる。 このケースでは, 変圧器井1について, 信号の流れる方向が ケース(a)とは逆にノード N3 からノード N2 であるため, $F$

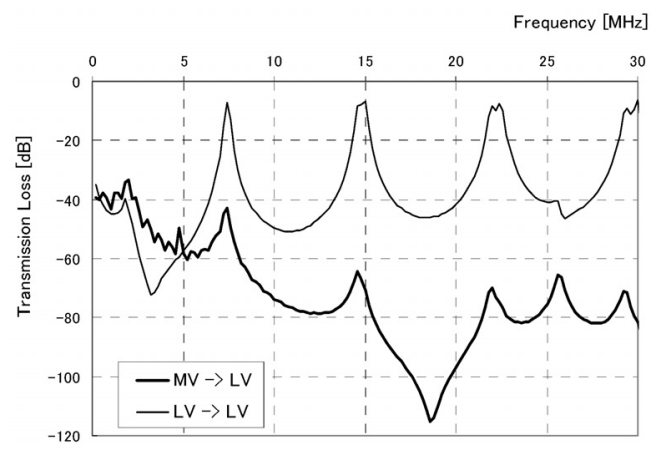

図 10 評価用系統でのシミュレーション結果

Fig. 10. Simulation results using test network model.

パラメータの值は $A$ と $D$ を入れ替えて使用する。

このように，提案した伝送路モデルの生成方法は，いず れのケースにおいても適用可能であることが分かる。なお, ケース(a)(b)での伝送特性シミュレーション結果を図 10 に 示す。

〈5·2〉 シミュレーション精度の検証 次に, 試験配 電系統における実測データとの比較により, 提案するシミ ユレーション手法の精度の検証を行った。試験に用いた配 電系統を図 11 に示す。図の試験配電系統は分岐を含む数種 類のケーブルと変圧器から構成される架空系統を模擬した 試験系統である。OW ケーブル・VV-F ケーブル・CV ケー ブルについては，〈3·3〉節および〈5・1〉節で述べた検証例 で用いたものと同じものを用いた。

電柱井2 に 6600V/100V の柱上変圧器が設置されており, 変圧器の 2 次側に OW ケーブルの配電線が接続されている。 また, 変圧器の近くに信号結合装置として CCU(Capacitive Coupling Unit)を設置している。この CCU は, 静電容量が 10nF のキャパシタを用いて作成したものである。

図中の\#1〜\#7 の位置には電柱が設置されており, それぞ れの電柱で 3 心の VV-F ケーブルの分岐がある。信号伝送に 用いる 2 本の線間に, 終端として $50 \Omega$ の抵抗が接続されて いる。ただし, 抵抗の両端にはキャパシタを設置して, 商 用周波数では線間は絶縁されるようにしている。なお, 試 験は系統電圧の $100 \mathrm{~V}$ を印加した状態で行った。

$\mathrm{CCU}$ に送信装置を接続し, 電柱の分岐からバランを介し て接続された受信装置間の通信速度を測定し, さらに, 送 信装置・受信装置を取り外して, 同じ設置位置にネットワ ークアナライザを接続し， $S$ パラメータの測定も行った。

配電盤については, 本研究ではインピーダンスをもたな い単なる分岐としてモデル化した。また，使用した信号結 合装置である CCUについてもモデル化した。

ネットワークアナライザによる伝送特性の実測結果と提 案手法によるシミュレーション結果を図 12 に示す。また, 3 パターンの周波数帯域におけるモデムによる通信速度の 実測結果と計算結果を表 2 に示す。表 2 において, 計算結 果は, 提案手法による伝送特性計算結果（図 12 の実線）を 用いて通信速度を計算した場合と, ネットワークアナライ ザによる伝送特性実測結果（図 12 の波線）を用いて通信速 


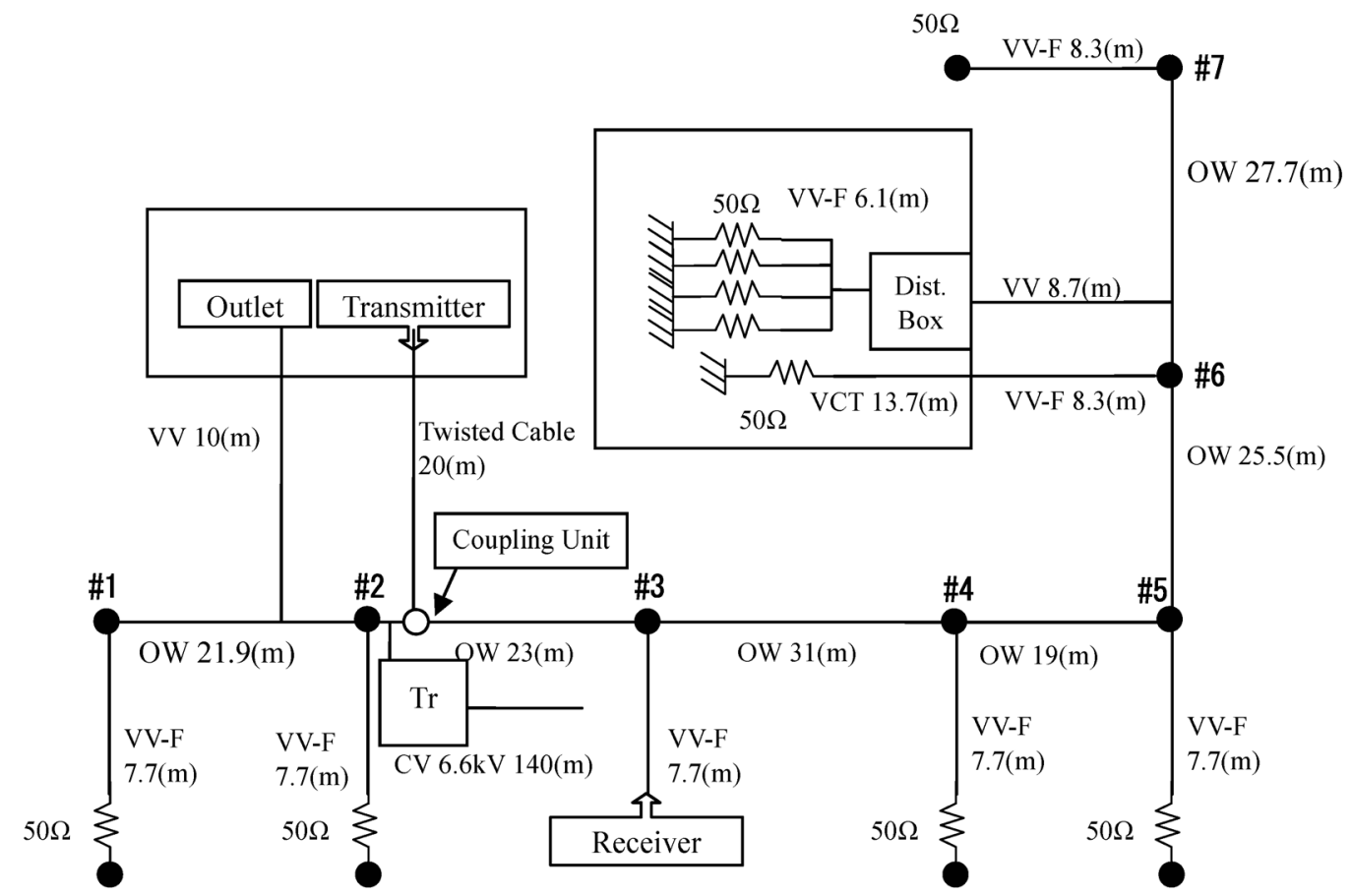

図 11 試験配電系統

Fig. 11. Test distribution network.

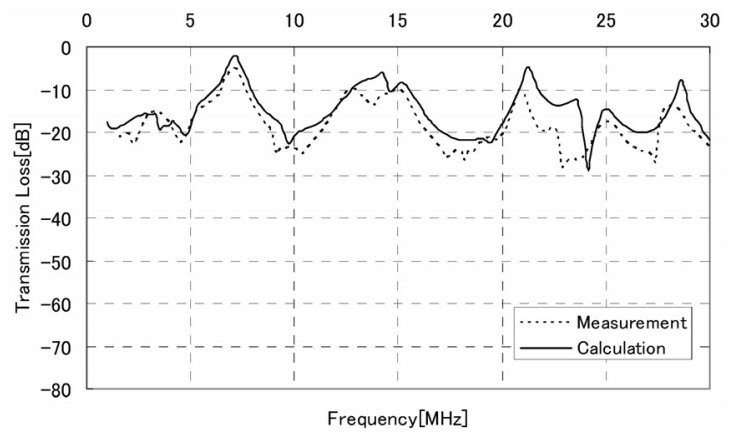

図 12 試験配電系統での伝送特性の比較

Fig. 12. Transmission Characteristics of calculation and measurement.

表 2 試験配電系統における通信速度の比較

Table 2. PHY rate of calculation and measurement.

\begin{tabular}{|c|c|c|c|}
\hline \multirow{2}{*}{$\begin{array}{c}\text { Freq. } \\
\text { Band }\end{array}$} & \multirow{2}{*}{$\begin{array}{c}\text { Measurement } \\
{[\mathrm{Mbps}]}\end{array}$} & \multicolumn{2}{|c|}{ Calculation [Mbps] } \\
\cline { 3 - 4 } & $\begin{array}{c}\text { Calculation by } \\
\text { Loss Calculation }\end{array}$ & $\begin{array}{c}\text { Calculation by } \\
\text { Loss Measurement }\end{array}$ \\
\hline \hline $\begin{array}{c}\text { Band1 } \\
(3-13 \mathrm{MHz})\end{array}$ & 75 & 82 & 77 \\
\hline $\begin{array}{c}\text { Band2 } \\
(14-24 \mathrm{MHz})\end{array}$ & 71 & 79 & 71 \\
\hline $\begin{array}{c}\text { Band3 } \\
(24-34 \mathrm{MHz})\end{array}$ & 69 & 74 & 65 \\
\hline
\end{tabular}

度を計算した結果の 2 種類の結果を示している。図 12 をみ ると, 提案手法での伝送特性計算結果と実測結果はほぼ一 致していることがわかる。また, 通信速度の実測結果と計 算結果についても，1 割程度の差異であることが確認でき る。これにより, 提案する伝送特性シミュレーション手法 で概略の通信速度を推定することが可能である。

\section{6. おわりに}

本稿では，アクセス系ネットワークを対象とし，配電系 統における任意の箇所に信号結合装置を設置した場合の信 号伝送特性を計算する手法を提案した。提案手法は，個々 の配電機器の伝送特性を 4 端子行列によるコンポーネント モデルとしてモデル化し, 信号結合装置の間の配電機器を トポロジーに沿って自動的に組み合わせることによってボ トムアップで伝送路モデルを生成し，伝送特性を計算する ものである。

配電線や変圧器，信号結合装置等についてコンポーネン トモデルを構築し，実測データとの比較によって，モデル の妥当性の評価を行った。

提案する伝送路モデル生成方法の有効性を示すために, 評価用系統において信号結合装置の設置位置を変えたケー スに対して，モデルが生成できることを確認した。また， 試験配電系統における実測データとの比較により，伝送特 性シミュレーションの妥当性の検証を実施した。

今後は，より大規模な実フィールドに適用することによ り，コンポーネントモデルの拡充と整備，ノイズ特性の同 定などの課題を克服すべく, 提案手法の更なる検証・評価 を継続していく予定である。

(平成 18 年 9 月 1 日受付, 平成 19 年 3 月 8 日再受付)

\section{文献}

（1）トリケップス企画部編：「電力線通信システム」，(株)トリケップス (2002) 
(2) K. Dostert and F. Verlag : "Powerline Communications", Prentice-Hall (2001)

( 3 ) J. Abe, Y. Murata, and M. Kitayama : "High Frequency Signal Injection and Transmission Characteristics Analysis in High Speed Power Line Communication", Electrical Review, Vol.90, No.3, pp.46-49 (2005) (in Japanese)

安部淳一・村田雄一郎・北山匡史 :「高速電力線通信における高周波 信号の注入と解析技術」, 電気評論, 90, 3, pp.46-49 (2005)

(4) J. Abe and M. Kitayama : "Network Topology Modeling Method for Channel Estimation on Power Line Communication", IEEJ Electron. Inf. And Syst. Soc. Conference, OS1-3 (2005) (in Japanese)

安部淳一・北山匡史 :「電力線通信における配電線モデル化の検討」, 平 17 電学電子・情報・システム部門大会, OS1-3 (2005)

( 5 ) M. Zimmermann and K. Dostert : "A Multipath Model for the Powerline Channel”, IEEE Trans. Communi., Vol.50, No.4, pp.553-559 (2002)

(6) I. C. Papaleonidopoulos, C. N. Capsalis, C. G. Karagiannopoulos, and N. J. Theodorou : "Statistical Analysis and Simulation of Indoor Single-Phase Low Voltage Power-Line Communication Channels on the basis of Multipath Propagation", IEEE Trans. Consumer Electronics, Vol.49, No.1, pp.89-99 (2003)

(7) D. Anastasiadou and T. Antonakoplulos : "Multipath Characterization of Indoor Power-Line Networks", IEEE Trans. Power Delivery, Vol.20, No.1, pp.90-99 (2005)

(8) S. Tsuzuki, T. Takamatsu, H. Nishio, and Y. Yamada : "An Estimation Method of the Transfer Function of Indoor Power-line Channels for Japanese Houses", Proc. 6th International Symposium on Power-Line Communications and Its Applications (ISPLC 2002), pp.55-59, Athens (2002)

(9) C. J. Kim and M. F. Chouikha : "Attenuation Characteristics of High Rate Home-Networking PLC Signals”, IEEE Trans. Power Delivery, Vol.17, No.4, pp.945-950 (2002)

(10) H. Meng, S. Chen, Y. L. Guan, C. L. Law, P. L. So, E. Gunawan, and T. T. Lie : "Modeling of Transfer Characteristics for the Broadband Power Line Communication Channel", IEEE Trans. Power Delivery, Vol.19, No.3, pp.1057-1064 (2004)

(11) S. Galli and T. Banwell : "A Novel Approach to the Modeling of the Indoor Power Line Channel - Part I: Circuit Analysis and Companion Model", IEEE Trans. Power Delivery, Vol.20, No.2, pp.655-663 (2005)

(12) S. Galli and T. Banwell : "A Novel Approach to the Modeling of the Indoor Power Line Channel - Part II: Transfer Function and Its Properties", IEEE Trans. Power Delivery, Vol.20, No.3, pp.869-878 (2005)

(13) T. Inada and Y. Namba : "Analytical Modeling of Transmission Characteristics of Distribution Line for High-Speed Power-Line Communication”, Technical Report of Matsushita Electric Works, Vol.53, No.4, pp.46-51 (2005) (in Japanese)

稲田 勉・難波嘉彦：「高速電力線通信における配電線の伝送特性解 析モデル」，松下電工技報, 53, 4, pp.46-51 (2005)

(14) H. Koga, N. Kodama, T. Konishi, and T. Gondo : "Power Line Communication Equipment using Wavelet OFDM Modem", IEEJ Electron. Inf. And Syst. Soc. Conference, OS1-1 (2004) (in Japanese) 古賀久雄・児玉宣貴・小西泰輔・権藤孝雄 :「Wavelet OFDM を用い た高速電力線通信実験一米国におけるフィールドテストー」, 平 16 電学電子・情報・システム部門大会, OS1-1 (2004)

(15) A. Mori, Y. Watanabe, M. Tokuda, and K. Kawamoto : "Transmission Characteristics of an OFDM signal for Power Line Communication System with High Bit Rate", T. IEE Japan, Vol.126, No.7, pp.810-817 (2006-7) (in Japanese)

森晃・渡邊陽介・徳田正満・河本康二 : 「高速電力線通信システ ムに対する OFDM 信号の伝送特性」, 電学論 C, 126, 7, pp.810-817 (2006-7)

(16) Y. Watanabe and M. Tokuda : "Influence of Ground Plane to the Distance Dependence of Leaked Electric Field from Power Line", IEEJ Electron. Inf. And Syst. Soc. Conference, OS1-5 (2004) (in Japanese) 渡辺陽介・徳田正満 :「電力線からの漏洩電界距離依存性に対する大 地面の影響」, 平 16 電学電子・情報・システム部門大会, OS1-5 (2004)

(17) R. Ishino, K. Takeshita, and T. Suzuki : "Power Line Communication Simulator of Low Voltage Distribution Lines with OFDM Modulator", Technical Report of CRIEPI, No.R00009 (2000) (in Japanese) 石野隆一・竹下和磨，鈴木 正：「高速電力搬送シミュレータの開発 -OFDM 通信方式を対象としたシミュレータの開発一」, 電力中央
研究所報告, R00009 (2000)

(18) H. Hirayama and T. Ohtsuki : Electric Circuit Theory Second Edition, IEEJ (2002) (in Japanese)

平山 博・大附辰夫 : 「電気回路論 2 版改訂」, 電気学会 (2002)

(19) K. Hara, S. Fujikawa, Y. Ootsu, Y. Tsubusaki, Y. Kimura, and S. Yamano : "Modeling of Propagation Characteristics for Power Feeding Cable", Proc. of the 2002 ICICE General Conference, B-8-30 (2002) (in Japanese) 原 和正・藤川就一・大津勇一・粒崎善弘・木村康郎・山野誠一 : 「電 力線用ケーブルの伝搬特性のモデル化」, 2002 年電子情報通信学会 総合大会, B-8-30 (2002)

(20) T. Takamatsu, S. Tsuzuki, and Y. Yamada : "Measurement of Distributed Constants of VVF Cable", IEICE Technical Report, SST2000-56 (2000) (in Japanese)

高松岳志・都築伸二・山田芳郎 :「VVF ケーブルの線路定数の測定」, 信学技報, SST2000-56 (2000)

(21) Y. Saito : Digital Modulation Techniques for Wireless Communications, IEICE (1996) (in Japanese)

斉藤洋一:「ディジタル無線通信の変復調」, 電子情報通信学会編 (1996)

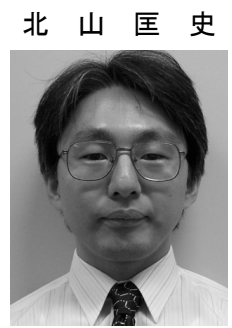

（上級会員）1989 年 3 月東京大学工学部電気工 学科卒業。1991 年 3 月同大学大学院工学系研究 科電気工学専攻課程修了。同年 4 月三菱電機 (株) 入社。先端技術総合研究にて電力系統シ ステムの計画・運用・保護に関する研究開発に 従事。2005 年電気学会進歩賞受賞。計測自動制 御学会, 資源・エネルギー学会, IEEEの会員。

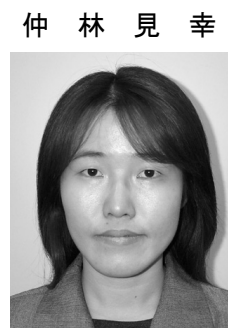

（正員） 1993 年 3 月お茶の水大学理学部数学 科卒業。同年 4 月三菱電機（株）入社。先端技 術総合研究所にて電力系統システムの計画・運 用・保護に関する研究開発に従事。

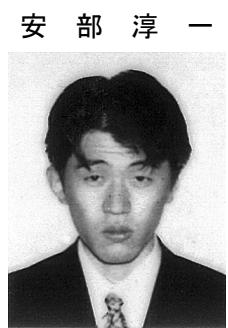

(非会員) 1998 年 3 月大阪大学工学部電気工学 科卒業。2000 年 3 月同大学大学院電気工学専攻 博士前期課程修了。同年 4 月三菱電機（株）入 社。先端技術総合研究所にて高速信号伝送およ び EMC に関する研究開発に従事。電子情報通 信学会会員。

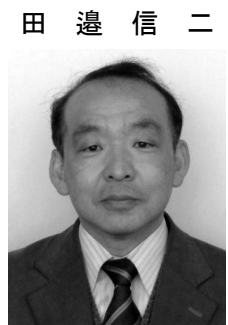

(非会員) 1980 年 3 月東北大学理学部物理学科 卒業。同年 4 月三菱電機 (株) 入社。1982 1983 年東北大学電気通信研究所研究員。1989 1990 年 University of Minnesota (MINT) 研究員。現 在, 先端技術総合研究所主管技師長。工学博士。 磁性体，電磁波・高速信号伝送関係の研究に従 事。電子情報通信学会, 日本応用磁気学会会員, IEEE Senior Member。 